Bull. Korean Math. Soc. 50 (2013), No. 3, pp. 777-786

http://dx.doi.org/10.4134/BKMS.2013.50.3.777

\title{
PROPER EFFICIENCY FOR SET-VALUED OPTIMIZATION PROBLEMS AND VECTOR VARIATIONAL-LIKE INEQUALITIES
}

\author{
Xian Jun Long, Jing Quan, And DaO-Jun Wen
}

\begin{abstract}
The purpose of this paper is to establish some relationships between proper efficiency of set-valued optimization problems and proper efficiency of vector variational-like inequalities under the assumptions of generalized cone-preinvexity. Our results extend and improve the corresponding results in the literature.
\end{abstract}

\section{Introduction}

The concept of vector variational inequality (for short, VVI) was first introduced and studied by Giannessi [10] in finite-dimensional spaces. Since then, VVIs have received much attention by many authors due to its potential application in vector optimization problems (for short, VOP), vector traffic equilibrium problems, economics, and management science. A great deal of results have appeared in the literature (see, for example $[9,11]$ and the references therein). It is well-known that a differentiable minimization problem is closely related to a variational inequality of differential type (see, e.g., [16]). This fact motivates researches to study the relation between a solution of the VVI and a solution of the VOP. Giannessi [12] obtained the relation between a solution of a Minty VVI and an efficient solution or a weakly efficient solution to the VOP under the assumptions of convexity. Yang et al. [25] generalized the results of [12] to pseudoconvexity. Recently, the VVI has been extended to the vector variational-like inequality (for short, VVLI). Yang and Yang [24] derived some relations between a solution of a Minty VVLI and an efficient solution or a weakly efficient solution to the VOP under the assumptions of pseudoinvexity. Al-Homidan and Ansari [1] also studied the relationship between the solution

Received February 19, 2012.

2010 Mathematics Subject Classification. 49J53, 90C26, 90C29.

Key words and phrases. set-valued optimization problem, vector variational-like inequality, proper efficiency, contingent epiderivative, generalized cone-preinvexity.

This work was supported by the National Natural Science Foundation of China (11001287), the Education Committee Project Research Foundation of Chongqing (KJ100711 and KJ110701), the Natural Science Foundation Project of Chongqing (CSTC 2010BB9254, CSTC2012jjA00039). 
to VVLIs and a efficient solution or a weakly efficient solution to nonsooth VOPs involving nondifferential invex functions. Very recently, Long et al. [19] generalized the results of [1] to nondifferential pseudoinvexity. For other results on this topic, we refer readers to $[2,3,4,17,20,22,23]$ and the references therein.

On the other hand, one of the most important problems in vector optimization theory is to find the efficient points of a set. However, some efficient points exhibit certain abnormal properties. To eliminate such anomalous efficient points, various concepts of proper efficiency have been introduced. In particular, Henig [14] introduced a class of properly efficient points, which is known as Henig properly efficient points in finite dimensional spaces. Borwein and Zhang [6] extended Henig properly efficiency to a normed space and also introduced the concept of super efficiency for the VOP. Gong [13] introduced the definition of Henig properly efficient solutions, globally properly efficient solutions and super efficient solutions for set-valued optimization problems (for short, SVOP) in locally convex spaces.

Recently, Liu and Gong [18] studied the relationships between proper efficiency of the VVI and proper efficiency of the VOP under the assumptions of convexity. Very recently, Zeng and Li [26] discussed the relation between a weakly efficient solution to the SVOP and a solution of VVLI involving generalized invexity.

We remark that, so far as we know, there are no paper dealing with the relation between proper efficiency of the SVOP and proper efficiency of the VVLI in locally convex spaces. This paper is the effort in this direction.

Motivated by the work in $[18,26]$, in this paper, we discuss the relation between proper efficiency of the SVOP and proper efficiency of the VVLI under the assumptions of generalized cone-preinvexity. Our results extend and improve the corresponding results of [18].

\section{Preliminaries}

Let $X$ be a real Hausdorff topological vector space and $Y$ be a real locally convex Hausdorff topological vector space. Let $C$ be a closed convex cone in $Y$ with a nonempty interior int $C$. The cone $C$ induces a partially ordering in $Y$ with the relations

$$
\begin{gathered}
y_{1} \leq y_{2} \Leftrightarrow y_{2}-y_{1} \in C ; \\
y_{1}<y_{2} \Leftrightarrow y_{2}-y_{1} \in \operatorname{int} C .
\end{gathered}
$$

Let $Y^{*}$ be the topological dual space of $Y$ and $C^{*}=\left\{f \in Y^{*}: f(x) \geq\right.$ 0 for all $x \in C$ \} be the dual cone of $C$. Denote the quasi-interior of $C^{*}$ by $C^{\sharp}$, i.e.,

$$
C^{\sharp}:=\left\{f \in Y^{*}: f(y)>0 \text { for all } y \in C \backslash\{0\}\right\} .
$$

Let $A$ be a nonempty subset of $X$, we denote the closure of $A$ by $\operatorname{cl}(A)$. A nonempty convex subset $B$ of $C$ is called a base of $C$ if $C=\operatorname{cone}(B)$ and 
$0 \notin \operatorname{cl}(B)$. It is well known that $C^{\sharp} \neq \emptyset$ if and only if $C$ has a base. Set $C^{\triangle}=\left\{f \in C^{\sharp}:\right.$ there exists $t>0$ such that $f(b) \geq t$ for all $\left.b \in B\right\}$.

By the separation theorem of convex sets, we know that $C^{\triangle} \neq \emptyset$. Obviously, $C^{\triangle} \subset C^{\sharp}$. Let $B$ be a base of $C$. Then, $0 \notin \operatorname{cl}(B)$. By the separation theorem of convex sets, there exists $f \in Y^{*} \backslash\{0\}$ such that

$$
r=\inf \{f(b): b \in B\}>f(0)=0 .
$$

Set $V_{B}=\left\{y \in Y:|f(y)|<\frac{r}{2}\right\}$. It follows that $V_{B}$ is an open convex circled neighborhood of 0 in $Y$. It is clear that

$$
\inf \left\{f(y): y \in B+V_{B}\right\} \geq \frac{r}{2} \text {. }
$$

Note that for any convex neighborhood $U$ of 0 with $U \subset V_{B}, B+U$ is a convex set and $0 \notin \operatorname{cl}(B+U)$. Therefore, $C_{U}(B):=\operatorname{cone}(B+U)$ is a pointed convex cone and $C \backslash\{0\} \subset \operatorname{int} C_{U}(B)$.

Let $K$ be a nonempty subset of $X, F: K \rightarrow 2^{Y}$ be a set-valued mapping. The set

$$
\operatorname{dom}(F):=\{x \in K: F(x) \neq \emptyset\}
$$

is called the domain of the mapping $F$. The set

$$
\operatorname{graph}(F):=\{(x, y) \in X \times Y: x \in K, y \in F(x)\}
$$

is called the graph of the mapping $F$. The set

$$
\operatorname{epi}(F):=\{(x, y) \in X \times Y: x \in K, y \in F(x)+C\}
$$

is called the epigraph of the mapping $F$.

We now recall some definitions and lemmas which will be used later.

Definition $2.1([7])$. Let $K$ be a nonempty subset of $X$ and $x_{0} \in \operatorname{cl} K$. The contingent cone $T\left(K, x_{0}\right)$ to $K$ at $x_{0}$ is the set of all $h \in X$ for which there exist a net $\left\{t_{\alpha}: \alpha \in I\right\}$ of positive real numbers and a net $\left\{x_{\alpha}: \alpha \in I\right\} \subset K$ such that

$$
\lim _{\alpha} x_{\alpha}=x_{0} \text { and } \lim _{\alpha} t_{\alpha}\left(x_{\alpha}-x_{0}\right)=h .
$$

Definition $2.2([8])$. Let $\left(x_{0}, y_{0}\right) \in \operatorname{graph}(F)$. The generalized contingent epiderivative $D F\left(x_{0}, y_{0}\right)$ of $F$ at $\left(x_{0}, y_{0}\right)$ is the set-valued mapping from $X$ to $Y$ defined by

$$
\operatorname{graph}\left(D F\left(x_{0}, y_{0}\right)\right)=T\left(\operatorname{epi}(F),\left(x_{0}, y_{0}\right)\right) .
$$

Remark 2.1. Let $\left(x_{0}, y_{0}\right) \in \operatorname{graph}(F)$. It is easy to see that

(i) $y \in D F\left(x_{0}, y_{0}\right)(x)$ if and only if there exist a net $\left\{\left(x_{\alpha}, y_{\alpha}\right): \alpha \in I\right\}$ in $\operatorname{epi}(F)$ and a net $\left\{t_{\alpha}: \alpha \in I\right\}$ of positive real numbers such that

$$
\lim _{\alpha}\left(x_{\alpha}, y_{\alpha}\right)=\left(x_{0}, y_{0}\right) \text { and } \lim _{\alpha} t_{\alpha}\left(x_{\alpha}-x_{0}, y_{\alpha}-y_{0}\right)=(x, y)
$$

(ii) the set-valued mapping $D F\left(x_{0}, y_{0}\right)$ is positively homogeneous with closed graphs. 
Definition 2.3 $([15])$. Let $\left(x_{0}, y_{0}\right) \in \operatorname{graph}(F)$. The contingent epiderivative $D_{c} F\left(x_{0}, y_{0}\right)$ of $F$ at $\left(x_{0}, y_{0}\right)$ is the vector-valued mapping from $X$ to $Y$ defined by

$$
\operatorname{epi}\left(D_{c} F\left(x_{0}, y_{0}\right)\right)=T\left(\operatorname{epi}(F),\left(x_{0}, y_{0}\right)\right) .
$$

Remark 2.2. From Definitions 2.2 and 2.3, we have

$$
y \in D F\left(x_{0}, y_{0}\right)(x) \text { if and only if } y \in D_{c} F\left(x_{0}, y_{0}\right)(x)+C .
$$

Let $\eta: K \times K \rightarrow X$ and $\varphi:[0,1] \rightarrow \mathbb{R}_{+}$be two given mappings with $\lim _{\lambda \rightarrow 0^{+}} \frac{\varphi(\lambda)}{\lambda}=k>0$.

Definition 2.4 ([21]). The set $K$ is said to be generalized invex with respect to $\eta$ and $\varphi$ if, for any $x, y \in K$ and $\lambda \in[0,1]$, we have $y+\varphi(\lambda) \eta(x, y) \in K$.

Definition 2.5. [21] Let $K$ be generalized invex with respect to $\eta$ and $\varphi$. The set-valued mapping $F: K \rightarrow 2^{Y}$ is said to be generalized $C$-preinvex on $K$ if for any $x, y \in K$ and $\lambda \in[0,1]$, one has

$$
\lambda F(x)+(1-\lambda) F(y) \subset F(y+\varphi(\lambda) \eta(x, y))+C .
$$

Remark 2.3. If $\varphi(\lambda)=\lambda$, then the generalized $C$-preinvex set-valued mapping is just the $C$-preinvex set-valued mapping which introduced by Bhatia and Mehra [5].

The following lemma will be used in the sequel which plays an important role in proving our main results.

Lemma $2.1([21])$. Let $\left(x_{0}, y_{0}\right) \in \operatorname{graph}(F)$. Let $K$ be a generalized invex set with respect to $\eta$ and $\varphi$ and the set-valued mapping $F: K \rightarrow 2^{Y}$ be generalized $C$-preinvex on $K$. Then

$$
F(x)-y_{0} \subset k D F\left(x_{0}, y_{0}\right)\left(\eta\left(x, x_{0}\right)\right), \forall x \in K .
$$

Let $K$ be a nonempty subset of $X, F: K \rightarrow 2^{Y}$ be a set-valued mapping and $C \subset Y$ be a closed convex cone. In this paper, we consider the following set-valued optimization problem (in short, SVOP):

$$
\min _{C} F(x) \text {, subject to } x \in K \text {. }
$$

We denote

$$
F(K)=\bigcup_{x \in K} F(x)
$$

Definition 2.6 ([13]). Let $\left(x_{0}, y_{0}\right) \in \operatorname{graph}(F)$.

(i) Let $B$ be a base of $C$. $\left(x_{0}, y_{0}\right)$ is called a Henig proper efficient solution of the SVOP, if there exists some neighborhood $U$ of 0 with $U \subset V_{B}$ such that

$$
\left(F(K)-y_{0}\right) \cap\left(-\operatorname{int} C_{U}(B)\right)=\emptyset .
$$


(ii) $\left(x_{0}, y_{0}\right)$ is called a globally proper efficient solution of the SVOP, if there exists a pointed convex cone $H \subset Y$ with $C \backslash\{0\} \subset \operatorname{int} H$ such that

$$
\left(F(K)-y_{0}\right) \cap((-H) \backslash\{0\})=\emptyset .
$$

(iii) $\left(x_{0}, y_{0}\right)$ is called a super efficient solution of the SVOP, if for each neighborhood $V$ of zero, there exists a neighborhood $U$ of zero such that

$$
\operatorname{cone}\left(F(K)-y_{0}\right) \cap(U-C) \subset V \text {. }
$$

\section{Generalized vector variational-like inequalities}

In this section, we discuss the relation between the proper efficient solution of set-valued optimization problems and the proper efficient solution of vector variational-like inequalities.

Let $\left(x_{0}, y_{0}\right) \in \operatorname{graph}(F)$. In the following, we always assume that $D F\left(x_{0}, y_{0}\right)$ exists, and $\eta\left(K, x_{0}\right)$ belongs to the domain of $D F\left(x_{0}, y_{0}\right)$.

In this section, we consider the following generalized vector variational-like inequality (in short, VVLI): find $x_{0} \in K$ and $y_{0} \in F\left(x_{0}\right)$ such that

$$
D F\left(x_{0}, y_{0}\right)\left(\eta\left(x, x_{0}\right)\right) \cap(-A)=\emptyset, \forall x \in K,
$$

where $A \cup\{0\}$ is a pointed convex cone.

Definition 3.1. Let $\left(x_{0}, y_{0}\right) \in \operatorname{graph}(F)$.

(i) Let $B$ be a base of $C$. $\left(x_{0}, y_{0}\right)$ is called a Henig proper efficient solution of the VVLI, if there exists some neighborhood $U$ of 0 with $U \subset V_{B}$ such that

$$
D F\left(x_{0}, y_{0}\right)\left(\eta\left(x, x_{0}\right)\right) \cap\left(-\operatorname{int} C_{U}(B)\right)=\emptyset, \forall x \in K .
$$

(ii) $\left(x_{0}, y_{0}\right)$ is called a globally proper efficient solution of the VVLI, if there exists a pointed convex cone $H \subset Y$ with $C \backslash\{0\} \subset \operatorname{int} H$ such that

$$
D F\left(x_{0}, y_{0}\right)\left(\eta\left(x, x_{0}\right)\right) \cap((-H) \backslash\{0\})=\emptyset, \forall x \in K \text {. }
$$

(iii) $\left(x_{0}, y_{0}\right)$ is called a super efficient solution of the VVLI, if for each neighborhood $V$ of zero, there exists a neighborhood $U$ of zero such that

$$
\operatorname{cone}\left(D F\left(x_{0}, y_{0}\right)\left(\eta\left(K, x_{0}\right)\right)\right) \cap(U-C) \subset V .
$$

Remark 3.1. If we assume $\eta\left(x, x_{0}\right)=x-x_{0}$ and replace $D F\left(x_{0}, y_{0}\right)$ by $D_{c} F\left(x_{0}, y_{0}\right)$, then Definition 3.1 reduces to the definition introduced by Liu and Gong [18].

Theorem 3.1. Let $B$ be a base of $C$. Let $K \subset X$ be a generalized invex set with respect to $\eta$ and $\varphi$, and the set-valued mapping $F: K \rightarrow 2^{Y}$ be generalized $C$-preinvex on $K$. Then $\left(x_{0}, y_{0}\right)$ is a Henig proper efficient solution of the $S V O P$ if and only if $\left(x_{0}, y_{0}\right)$ is a Henig proper efficient solution of the VVLI. 
Proof. If $\left(x_{0}, y_{0}\right)$ is a Henig proper efficient solution of the SVOP, then there exists some neighborhood $U$ of 0 with $U \subset V_{B}$ such that

$$
\left(F(K)-y_{0}\right) \cap\left(-\operatorname{int} C_{U}(B)\right)=\emptyset .
$$

Suppose by contradiction that for the above $U \subset V_{B}$, there exists $x \in K$ such that

$$
D F\left(x_{0}, y_{0}\right)\left(\eta\left(x, x_{0}\right)\right) \cap\left(-\operatorname{int} C_{U}(B)\right) \neq \emptyset \text {. }
$$

Let

$$
y \in D F\left(x_{0}, y_{0}\right)\left(\eta\left(x, x_{0}\right)\right) \cap\left(-\operatorname{int} C_{U}(B)\right) .
$$

By the definition of generalized contingent epiderivative,

$$
\left(\eta\left(x, x_{0}\right), y\right) \in \operatorname{graph}\left(D F\left(x_{0}, y_{0}\right)\right)=T\left(\operatorname{epi}(F),\left(x_{0}, y_{0}\right)\right) .
$$

It follows that there exist a net $\left\{\left(x_{\alpha}, y_{\alpha}\right): \alpha \in I\right\}$ in epi $(F)$ and a net $\left\{t_{\alpha}: \alpha \in\right.$ $I\}$ of positive real numbers such that

$$
\lim _{\alpha}\left(x_{\alpha}, y_{\alpha}\right)=\left(x_{0}, y_{0}\right) \text { and } \lim _{\alpha} t_{\alpha}\left(x_{\alpha}-x_{0}, y_{\alpha}-y_{0}\right)=\left(\eta\left(x, x_{0}\right), y\right) .
$$

Since $y \in-\operatorname{int} C_{U}(B)$ and $y=\lim _{\alpha} t_{\alpha}\left(y_{\alpha}-y_{0}\right)$, there exists $\alpha_{0} \in I$ such that

$$
t_{\alpha}\left(y_{\alpha}-y_{0}\right) \in-\operatorname{int} C_{U}(B) \text { for all } \alpha \geq \alpha_{0} .
$$

This implies that

$$
y_{\alpha}-y_{0} \in-\operatorname{int} C_{U}(B) \text { for all } \alpha \geq \alpha_{0}
$$

and so

$$
y_{\alpha} \in y_{0}-\operatorname{int} C_{U}(B) \text { for all } \alpha \geq \alpha_{0} .
$$

Since $\left\{\left(x_{\alpha}, y_{\alpha}\right)\right\} \subset \operatorname{epi}(F)$, there exist $y_{\alpha}^{\prime} \in F\left(x_{\alpha}\right)$ and $c_{\alpha} \in C$ such that

$$
y_{\alpha}=y_{\alpha}^{\prime}+c_{\alpha} .
$$

Note that $\operatorname{int}_{U}(B)+C \subset \operatorname{int} C_{U}(B)$. This fact together with (2) and (3) yields

$$
y_{\alpha}^{\prime}=y_{\alpha}-c_{\alpha} \in y_{0}-\operatorname{int} C_{U}(B)-C \subset y_{0}-\operatorname{int} C_{U}(B) \text { for all } \alpha \geq \alpha_{0},
$$

which contradicts $(1)$ since $y_{\alpha}^{\prime} \in F\left(x_{\alpha}\right) \subset F(K)$.

Conversely, let $\left(x_{0}, y_{0}\right)$ be a Henig proper efficient solution of the VVLI.

Then there exists some neighborhood $U$ of 0 with $U \subset V_{B}$ such that

$$
D F\left(x_{0}, y_{0}\right)\left(\eta\left(x, x_{0}\right)\right) \cap\left(-\operatorname{int} C_{U}(B)\right)=\emptyset, \forall x \in K .
$$

Since $\operatorname{int}_{U}(B)$ is a convex cone and $k>0$,

$$
k D F\left(x_{0}, y_{0}\right)\left(\eta\left(x, x_{0}\right)\right) \cap\left(-\operatorname{int} C_{U}(B)\right)=\emptyset, \forall x \in K .
$$

This fact together with Lemma 2.1 yields

$$
\left(F(K)-y_{0}\right) \cap\left(-\operatorname{int} C_{U}(B)\right)=\emptyset .
$$

Therefore, $\left(x_{0}, y_{0}\right)$ is a Henig proper efficient solution of the SVOP. This completes the proof. 
Theorem 3.2. Let $K \subset X$ be a generalized invex set with respect to $\eta$ and $\varphi$, and the set-valued mapping $F: K \rightarrow 2^{Y}$ be generalized $C$-preinvex on $K$. Then $\left(x_{0}, y_{0}\right)$ is a globally proper efficient solution of the SVOP if and only if $\left(x_{0}, y_{0}\right)$ is a globally proper efficient solution of the VVLI.

Proof. Let $\left(x_{0}, y_{0}\right)$ be a globally proper efficient solution of the SVOP. Then, there exists a pointed convex cone $H \subset Y$ with $C \backslash\{0\} \subset \operatorname{int} H$ such that

$$
\left(F(K)-y_{0}\right) \cap((-H) \backslash\{0\})=\emptyset .
$$

Suppose by contradiction that $\left(x_{0}, y_{0}\right)$ is not a globally proper efficient solution of the VVLI. Thus, for any pointed convex cone $H_{1} \subset Y$ with $C \backslash\{0\} \subset \operatorname{int} H_{1}$, there exists $x \in K$ such that

$$
D F\left(x_{0}, y_{0}\right)\left(\eta\left(x, x_{0}\right)\right) \cap\left(\left(-H_{1}\right) \backslash\{0\}\right) \neq \emptyset .
$$

Let $y \in D F\left(x_{0}, y_{0}\right)\left(\eta\left(x, x_{0}\right)\right) \cap\left(\left(-H_{1}\right) \backslash\{0\}\right)$. By the definition of generalized contingent epiderivative,

$$
\left(\eta\left(x, x_{0}\right), y\right) \in \operatorname{graph}\left(D F\left(x_{0}, y_{0}\right)\right)=T\left(\operatorname{epi}(F),\left(x_{0}, y_{0}\right)\right) .
$$

Thus there exist a net $\left\{\left(x_{\alpha}, y_{\alpha}\right): \alpha \in I\right\}$ in epi $(F)$ and a net $\left\{t_{\alpha}: \alpha \in I\right\}$ of positive real numbers such that

$$
\lim _{\alpha}\left(x_{\alpha}, y_{\alpha}\right)=\left(x_{0}, y_{0}\right) \text { and } \lim _{\alpha} t_{\alpha}\left(x_{\alpha}-x_{0}, y_{\alpha}-y_{0}\right)=\left(\eta\left(x, x_{0}\right), y\right) .
$$

It follows that there exists $\alpha_{0} \in I$ such that

$$
y_{\alpha}-y_{0} \in\left(-H_{1}\right) \backslash\{0\} \text { for all } \alpha \geq \alpha_{0} .
$$

Since $\left\{\left(x_{\alpha}, y_{\alpha}\right)\right\} \subset \operatorname{epi}(F)$, there exist $y_{\alpha}^{\prime} \in F\left(x_{\alpha}\right)$ and $c_{\alpha} \in C$ such that

$$
y_{\alpha}=y_{\alpha}^{\prime}+c_{\alpha} .
$$

This fact together with (5) yields

$$
y_{\alpha}^{\prime}=y_{\alpha}-c_{\alpha} \in y_{0}-H_{1} \backslash\{0\}-C \subset y_{0}-H_{1} \backslash\{0\} \text { for all } \alpha \geq \alpha_{0},
$$

which contradicts (4).

Conversely, let $\left(x_{0}, y_{0}\right)$ be a globally proper efficient solution of the VVLI. Then, there exists a pointed convex cone $H \subset Y$ with $C \backslash\{0\} \subset \operatorname{int} H$ such that

$$
D F\left(x_{0}, y_{0}\right)\left(\eta\left(x, x_{0}\right)\right) \cap((-H) \backslash\{0\})=\emptyset, \forall x \in K .
$$

Similar to the proof of Theorem 3.1, we can obtain that $\left(x_{0}, y_{0}\right)$ is a globally proper efficient solution of the SVOP. This completes the proof.

Theorem 3.3. Let $K \subset X$ be a generalized invex set with respect to $\eta$ and $\varphi$, and the set-valued mapping $F: K \rightarrow 2^{Y}$ be generalized $C$-preinvex on $K$. Then $\left(x_{0}, y_{0}\right)$ is a super efficient solution of the SVOP if and only if $\left(x_{0}, y_{0}\right)$ is a super efficient solution of the VVLI. 
Proof. Since $Y$ is a topological vector space, for each neighborhood $V$ of zero, there exists a neighborhood $V_{1}$ of zero such that $\operatorname{cl} V_{1} \subset V$. Let $\left(x_{0}, y_{0}\right)$ be a super efficient solution of the SVOP. Then, for above $V_{1}$, there exists a neighborhood $U$ of zero such that

$$
\operatorname{cone}\left(F(K)-y_{0}\right) \cap(U-C) \subset V_{1} .
$$

For any $z \in \operatorname{cone}\left(D F\left(x_{0}, y_{0}\right)\left(\eta\left(K, x_{0}\right)\right)\right) \cap(U-C)$, there exist

$$
y \in D F\left(x_{0}, y_{0}\right)\left(\eta\left(K, x_{0}\right)\right)
$$

and $\lambda \geq 0$ such that

$$
z=\lambda y \in U-C .
$$

Since $y \in D F\left(x_{0}, y_{0}\right)\left(\eta\left(K, x_{0}\right)\right)$, similar to the proof of Theorem 3.1, there exists $\left\{\left(x_{\alpha}, y_{\alpha}: \alpha \in I\right)\right\}$ in epi $(F)$ such that $y=\lim _{\alpha} t_{\alpha}\left(y_{\alpha}-y_{0}\right)$. This fact together with (7) yields

$$
\lim _{\alpha} \lambda\left(t_{\alpha}\left(y_{\alpha}-y_{0}\right)\right)=z \in U-C .
$$

It follows that there exists $\alpha_{0} \in I$ such that

$$
\lambda\left(t_{\alpha}\left(y_{\alpha}-y_{0}\right)\right) \in U-C, \forall \alpha \geq \alpha_{0} .
$$

On the other hand,

$$
\lambda\left(t_{\alpha}\left(y_{\alpha}-y_{0}\right)\right) \in \lambda\left(t_{\alpha}\left(F(K)-y_{0}\right)\right) \subset \operatorname{clcone}\left(F(K)-y_{0}\right) .
$$

Therefore,

$$
z \in \operatorname{clcone}\left(F(K)-y_{0}\right) \cap(U-C) \subset \operatorname{cl} V_{1} \subset V,
$$

which implies that

$$
\operatorname{cone}\left(D F\left(x_{0}, y_{0}\right)\left(\eta\left(K, x_{0}\right)\right)\right) \cap(U-C) \subset V .
$$

Hence, $\left(x_{0}, y_{0}\right)$ is a super efficient solution of the VVLI.

Conversely, by Lemma 2.1,

$$
F(x)-y_{0} \subset k D F\left(x_{0}, y_{0}\right)\left(\eta\left(K, x_{0}\right)\right) .
$$

It follows that

$$
\operatorname{cone}\left(F(x)-y_{0}\right) \subset \operatorname{cone}\left(D F\left(x_{0}, y_{0}\right)\left(\eta\left(K, x_{0}\right)\right)\right) .
$$

Since $\left(x_{0}, y_{0}\right)$ is a super efficient solution of the VVLI, for each neighborhood $V$ of zero, there exists a neighborhood $U$ of zero such that

$$
\operatorname{cone}\left(D F\left(x_{0}, y_{0}\right)\left(\eta\left(K, x_{0}\right)\right)\right) \cap(U-C) \subset V .
$$

Combining (8) and (9) yields

$$
\operatorname{cone}\left(F(x)-y_{0}\right) \cap(U-C) \subset V .
$$

Therefore, $\left(x_{0}, y_{0}\right)$ is a super efficient solution of the SVOP. This completes the proof.

Remark 3.2. It is worth mentioning that the assumption of generalized $C$ preinvexity is only needed for the proof of the sufficiency of Theorems 3.1-3.3. 
Remark 3.3. Theorems 3.1-3.3 generalize and improve the corresponding results of Liu and Gong [18] in the following three aspects:

(i) The setting of normed spaces is generalized to locally convex spaces.

(ii) The constraint set which is a convex set is extended to the generalized invex set.

(iii) The $C$-convexity of $F$ is extended to generalized $C$-preinvexity.

\section{References}

[1] A. Al-Homidan and Q. H. Ansari, Generalized Minty vector variational-like inequalities and vector optimization problems, J. Optim. Theory Appl. 144 (2010), no. 1, 1-11.

[2] Q. H. Ansari and G. M. Lee, Nonsmooth vector optimization problems and Minty vector variational inequalities, J. Optim. Theory Appl. 145 (2000), no. 1, 1-16.

[3] Q. H. Ansari, M. Rezaie, and J. Zafarani, Generalized vector variational-like inequalities and vector optimization, J. Global Optim. 53 (2012), no. 2, 271-284.

[4] Q. H. Ansari and J. C. Yao, On nondifferentiable and nonconvex vector optimization problems, J. Optim. Theory Appl. 106 (2000), no. 3, 475-488.

[5] D. Bhatia and A. Mehra, Lagrangian duality for preinvex set-valued functions, J. Math. Anal. Appl. 214 (1997), no. 2, 599-612.

[6] J. M. Borwein and D. Zhang, Super efficiency in vector optimization, Trans. Amer. Math. Soc. 338 (1993), no. 1, 105-122.

[7] G. Bouligand, Sur l'existence des demi-tangentes á une courbe de Jordan, Fundamenta Math. 15 (1930), 215-215.

[8] H. W. Corley, Optimality conditions for maximizations of set-valued functions, J. Optim. Theory Appl. 58 (1988), no. 1, 1-10.

[9] G. Y. Chen, X. X. Huang, and X. Q. Yang, Vector Optimization: Set-Valued and Variational Analysis, Springer-Verlag, Berlin, Heidelberg, 2005.

[10] F. Giannessi, Theorem of alternative, quadratic programs, and complementarity problem, In: R. W. Cottle, F. Giannessi, J. L. Lions(Eds.), Variational Inequality and Complementarity Problem, pp. 151-186. John Wiley and Sons, Chichester, UK, 1980.

[11] — Vector Variational Inequilities and Vector Equilibria: Mathematical Theories, Kluwer Academic, Dordrechet, 2000.

[12] _ On Minty variational principle, In: F. Giannessi, S. Komlósi, T. Tapcsáck(eds.), New Trends in Mathematical Programming, pp. 93-99. Kluwer Academic, Dordrechet, 1998.

[13] X. H. Gong, Optimality conditions for Henig and globally proper efficient solutions with ordering cone has empty interior, J. Math. Anal. Appl. 307 (2005), no. 1, 12-31.

[14] M. I. Henig, Proper efficiency with respect to cones, J. Optim. Theory Appl. 36 (1982), no. $3,387-407$.

[15] J. Jahn and R. Rauh, Contingent epiderivatives and set-valued optimization, Math. Methods Oper. Res. 46 (1997), no. 2, 193-211.

[16] D. Kinderlehrer and G. Stampacchia, An Introduction to Variational Inequalities and their Applications, Academic Press, New York, 1980.

[17] G. M. Lee, D. S. Kim, B. S. Lee, and N. D. Yen, Vector variational inequalities as a tool for studying vector optimization problems, Nonlinear Anal. 34 (1998), no. 5, 745-765.

[18] W. Liu and X. H. Gong, Proper efficiency for set-valued vector optimization problems and vector variational inequalities, Math. Methods Oper. Res. 51 (2000), no. 3, 443-457.

[19] X. J. Long, J. W. Peng, and S. Y. Wu, Generalized vector variational-like inequalities and nonsmooth vector optimization problems, Optimization 61 (2012), 1075-1086.

[20] S. K. Mishra and S. Y. Wang, Vector variational-like inequalities and non-smooth vector optimization problems, Nonlinear Anal. 64 (2006), no. 9, 1939-1945. 
[21] J. H. Qiu, Cone-directed contingent derivatives and generalized preinvex set-valued optimization, Acta Math. Sci. Ser. B Engl. Ed. 27 (2007), no. 1, 211-218.

[22] M. Rezaie and J. Zafarani, Vector optimization and variational-like inequalities, J. Global Optim. 43 (2009), no. 1, 47-66.

[23] G. Ruiz-Garzón, R. Osuna-Gómez, and A. Rufián-Lizana, Relationships between vector variational-like inequality and optimization problems, European J. Oper. Res. 157 (2004), no. 1, 113-119.

[24] X. M. Yang and X. Q. Yang, Vector variational-like inequality with pseudoinvexity, Optimization 55 (2006), no. 1-2, 157-170.

[25] X. M. Yang, X. Q. Yang, and K. L. Teo, Some remarks on the Minty vector variational inequality, J. Optim. Theory Appl. 121 (2004), no. 1, 193-201.

[26] J. Zeng and S. J. Li, On vector variational-like inequalities and set-valued optimization problems, Optim. Lett. 5 (2011), no. 1, 55-69.

Xian Jun LONG

College of Mathematics and Statistics

Chongqing Technology and Business University

ChONGQING 400067, P. R. China

E-mail address: xianjunlong@hotmail.com

JING QUAN

Department of Mathematics

YIBIN UNIVERSITY

Yibin, Sichuan 644007, P. R. China

E-mail address: quanjingcq@163.com

DAO-JUn WEN

College of Mathematics and Statistics

Chongqing Technology and Business University

Chongqing 400067, P. R. China

E-mail address: daojunwen@163.com 